\title{
The qualities of a good teacher: how can they be acquired and sustained?
}

Samy A Azer MB PhD

J R Soc Med 2005;98:67-69

The introduction of problem-based learning (PBL) in undergraduate medical courses necessitates the special training of teachers and monitoring of their performance. ${ }^{1}$ In traditional courses the emphasis is on transmission of factual knowledge; teachers are the main source of information and students are offered few opportunities to identify their own learning needs or reflect collectively on their learning experience. ${ }^{2}$ Then, if the outcomes are unfavourable, the blame lies with the student, for lack of skills or motivation. By contrast, in PBL courses the responsibilities of teachers include: encouraging critical thinking; fostering self-directed learning and curiosity; monitoring group progress; and creating a learning environment that stimulates all members in the group, generates deep understanding, and promotes teamwork. ${ }^{1,3}$

These activities demand special attributes. Over the past five years I have run over forty workshops for would-be PBL tutors as well as refresher workshops for existing tutors who wish to enhance their skills as PBL facilitators. These workshops usually begin with a session titled What makes good teachers? and I ask participants to write down the name of the best teacher they have ever had and list his or her good qualities: 'In what way did your best teacher help you to grow?' Certain qualities are common to many of these teachers - for example, 'He treated me with respect and was interested in helping and supporting me'; 'She motivated me to love the subject she was teaching'; 'She created a positive impact on my life that reshaped my vision and purpose'; 'He was able to keep us engaged in his lessons, think, and ask good questions'; 'I realized that learning can be fun and a life-long experience'. These responses stimulated me to examine the qualities of a good teacher in a more systematic way.

\section{ROLE MODELS}

Role modelling is thought to be an integral component of medical education. We identify people as role models when they inspire imitation and influence people working with them to develop new skills and achieve their potential. ${ }^{4,5}$

Faculty Education Unit, Faculty of Medicine, Dentistry and Health Sciences, Medical Building, Level 7, North Wing, University of Melbourne, Parkville 3010, Victoria, Australia

E-mail: Samy@unimelb.edu.au
Students learn from continuous observation of the ways their teachers handle difficult and stressful situations, how they relate to their patients, and how they deal with ethical and moral issues.

In one recent study, the most highly regarded teachers in a large department of medicine were asked to specify the personal qualities, teaching skills and clinical competencies they considered most critical for effective role modelling in medicine. ${ }^{6}$ The findings indicated that good teachers are enthusiastic, friendly, easy-going, able to develop rapport with learners, committed to the growth of their students, approachable, interested in learners as people, and always conscious of their status as role models. The participants were then asked to list barriers to effective modelling and these included being quiet, being overextended, having difficulty remembering names and being impatient and impulsive.

Is ethnic background or culture relevant to the choice of role models in medical schools? The answer is yes, 7,8 and this needs to be borne in mind in selection of faculty teaching staff and appointment of teaching and assessment committees. ${ }^{9}$ All medical educators should be aware of the impact of cultural differences on learning.

A search of the Medline and HighWire databases under 'good teachers' and 'mentors' indicates that the subject attracts growing attention. From January 1978 to December 2003 the number of publications was 1061, of which just over half appeared in the last 4 years. Box 1 lists the qualities of a good teacher highlighted in this published work, under categories derived from my own experience.

\section{PROMOTING EXCELLENCE IN TEACHING}

In PBL courses, the usual rewards for excellent teaching are personal prizes, grants for research in education, or funding to attend professional development courses. Among the benefits are the encouragement of young tutors to develop careers in medical education and establishment of links with local and international educators and researchers in medical education. A good tutor training programme fosters the arts of facilitation, group dynamics, and feedback. ${ }^{10-13}$ Faculty training and mentoring programmes should be part of university policies for the promotion of academic excellence. ${ }^{14}$ One initial training session for faculty 
1 Committed to the work

Focuses on educational needs of the students

Works with passion

Keen to uphold the university's values

Enthusiastic about work and about teaching

2 Encourages and appreciates diversity

Does not stereotype or speak negatively of others

Nurtures and encourages diversity

Seeks and encourages understanding of, and respect for people of diverse backgrounds

3 Interacts and communicates respect

Communicates effectively with others

Encourages input from others, listening deeply and giving credit for their contributions

Acts with integrity

Provides a model of high ethical standards

Shows a caring attitude

4 Motivates students and co-workers

Encourages students to achieve their goals

Provides constructive feedback

Monitors progress of students and fosters their success

5 Brings a wide range of skills and talents to teaching

Teaching is clearly presented and stimulates high-order thinking skills

Presents difficult concepts comprehensibly

Brings appropriate evidence to the critique

Teaches memorably

6 Demonstrates leadership in teaching

Contributes to course design and structure

Contributes to publications on education

Evidence of self-development in an educational context

Demonstrates creativity in teaching strategies

Committed to professional development in education
7 Encourages an open and trusting learning environment Creates a climate of trust

Encourages students to learn from mistakes

Helps students redefine failure as a learning experience

Encourages student questions and engagement in the learning process

Encourages student growth with appropriate behaviourbased feedback

8 Fosters critical thinking

Teaches students how to think, not what to think

Encourages students to organize, analyse and evaluate

Explores with probing questions

Discusses ideas in an organized way

Helps students to focus on key issues

Trains students in strategic thinking

9 Encourages creative work

Motivates students to create new ideas

Fosters innovation and new approaches

10 Emphasizes teamwork

Builds links at national and international levels in education

Encourages students to work in teams

Encourages collaborative learning

11 Seeks continually to improve teaching skills

Seeks to learn and incorporate new skills, and information teaching

Seeks feedback and criticism

Keeps up to date in specialty

12 Provides positive feedback

Listens to students and discovers their educational needs

Values students, never belittles

Provides constructive feedback

Helps and supports people to grow

Teaches students how to monitor their own progress. development at the beginning of a project (e.g., introduction of PBL) is not enough. Follow-up mentoring, coupled with opportunities to share ideas with other tutors as new skills are developed, is crucial to successful implementation of a new curriculum. ${ }^{14,15}$ The academies of medical educators at Harvard Medical School and the University of California San Francisco (UCSF) are two examples of current trends in medical and health education. At Harvard, the academy aims to reward excellence in teaching and provide a forum for the exchange of ideas across departmental and institutional lines. ${ }^{16}$ The academy at UCSF likewise rewards talent and has also initiated a mentoring programme to help junior faculty members enhance their teaching skills. ${ }^{17}$ One aim of faculty development programmes is to improve teachers' abilities to write high-quality and reliable test questions. Assessment of students' cognitive skills is a much neglected area in curriculum change. ${ }^{18}$

\section{ChAllenges}

The emerging changes in medical curricula and the role of medical teachers necessitates the development of standards for medical education at international as well as national levels. ${ }^{19-21}$ As research becomes the main criterion for promotion in academia, faculty time for education is at risk. ${ }^{22}$ This is one of the main challenges facing educators in universities worldwide. Vice-chancellors and deans need to reassess the criteria for academic promotion and allocate more credit for education. A second challenge is the lack of training and mentoring programmes in medical and health professional schools. Although the introduction of PBL has 
necessitated the development of training programmes in most schools, these need to be backed by mentoring and continuous support for new tutors. A third challenge is the separation of research from education, and the consequent lack of established knowledge in areas such as staff development and enhancement of teaching skills. ${ }^{23} \mathrm{~A}$ fourth challenge is the lack of resources for training teachers and junior faculty academics.

\section{CONCLUSIONS}

The advent of PBL has cast a spotlight on the qualities of a good teacher. Excellent teachers serve as role models, influence career choices and enable students to reach their potential. Some of the necessary qualities are inherent, others can be acquired. In medical schools the good teachers must be nurtured and rewarded.

Note The author chaired the Subcommittee of Excellence in Teaching Awards, Faculty of Medicine, Dentistry and Health Sciences, the University of Melbourne, 2003-2004.

\section{REFERENCES}

1 Barrows HS. Problem-based learning in medicine and beyond. A brief overview. In: Wilkerson L, Gijselaers WH, eds. Bringing Problem-based Learning to Higher Education: Theory and Practice, Number 68. San Francisco: Jossey-Bass, 1996

2 Norman GR, Schmidt HG. The psychological basis of problem-based learning: a review of the evidence. Acad Med 1992;67:557-65

3 Wilkerson L. Tutors and small groups in problem-based learning: lessons from the curricula. Ann Intern Med 1998;129:734-97

4 Paice E, Heard S, Moss F. How important are role models in making good doctors? BMJ 2002;325:707-10

5 Wright SM, Kern DE, Kolodner K, Howard DM, Brancati FL. Attributes of excellent attending-physician role models. N Engl J Med 1998;339:1986-93

6 Wright SM, Carrese JA. Excellence in role modeling: insight and perspectives from the pros. Can Med Assoc J 2002;167:638-43
7 McLean M. Is culture important in the choice of role models? Experience from a culturally diverse medical school. Med Teacher 2004;26:142-9

8 Prideaux D. Is valuing ethnic diversity enough? Should we expect ethnically and culturally safe practice? Med Teacher 1999;33:555-6

9 Das Carlo M, Swadi H, Mpofu D. Medical student perceptions of factors affecting productivity of problem-based learning tutorial groups: does culture influence the outcomes? Teach Learn Med 2003; 15:59-64

10 Evans PA, Taylor DCM. Staff development of tutor skills for problembased learning. Med Educ 1996;30:365-6

11 Farmer EA. Faculty development for problem-based learning. Europ J Dentistry Ed 2004;8:59-66

12 Grand' Maison P, Desmarchais JE. Preparing faculty to teach in a problem-based learning curriculum: The Sherbrooke experience. Can Med Assoc J 1991;144:557-62

13 Azer SA. Becoming a PBL Tutor. Material Used in a Two-day Training Workshop. Melbourne: Faculty Education Unit, University of Melbourne, 2002

14 Wilkerson L, Irby DM. Strategies for improving teaching practices: a comprehensive approach to faculty development. Acad Med 1998;73:387-96

15 Guskey TR. Professional development and teacher change. Teachers and Teaching: Theory and Practice 2002;8:381-91

16 Thibault GE, Neill JM, Lowenstein DH. The academy at Harvard medical school: nurturing teaching and stimulating innovation. Acad Med 2003;78:673-81

17 Cooke M, Irby DM, Debas HT. The UCSF academy of medical educators. Acad Med 2003;78:666-72

18 Azer SA. Assessment in a problem-based learning course: twelve tips for constructing multiple choice questions that test students' cognitive skills. Biochem Molec Biol Ed 2003;31:428-34

19 Hamilton JD. Establishing standards and measurement methods for medical education. Acad Med 1995;70:51-6

20 Hamilton JD. International standards of medical education: a global responsibility. Med Teacher 2000;22:555-9

21 Purcell N, Lloyd-Jones G. Standards for medical educators. Med Ed 2003;37:149-54

22 Whitcombe ME. Medical education research. Acad Med 2004;79:907

23 Prideaux D. Promises and delivery - a research imperative for new approaches to medical education. BMJ 2004;329:331-2 